\title{
An Efficient One-pot $N$-Acylation of Deoxy- and Ribo-cytidine Using Carboxylic Acids Activated in situ with 2-Chloro-4,6-dimethoxy-1,3,5-triazine
}

\author{
Ambadas B. Rode, Sang Jun Son, ${ }^{\dagger}$ and In Seok Hong* \\ Department of Chemistry, Kongju National University, Kongju, Chungnam 314-701, Korea. *E-mail: ishong@kongju.ac.kr \\ ${ }^{\dagger}$ College of BioNano Technology, Kyungwon University, Gyeonggi 461-701, Korea \\ Received May 2, 2010, Accepted May 14, 2010
}

Key Words: Selective acylation, Nucleoside protection, 2-Chloro-4,6-dimethoxy-1,3,5-triazine, Activated acyl group, Single-step protection

Synthetic oligonucleotides (ODNs) are an emerging class of drug molecules with a broad spectrum for therapeutic applications. In the ODNs synthesis, a fundamental process is the internucleotide-bond formation achieved via the condensation of a nucleoside and a suitably activated nucleoside such as the phosphoryl, H-phosphoryl, or phosphoramidite species. In this step, when the substances without the protection of the nucleobase are used, the exocyclic amino group of the adenine and cytosine moieties, and sometimes that of the guanine moiety, undergoes undesired modification. Accordingly, protection of the amino function is required to achieve the desired internucleotide linkage construction. Thus, the invention of amino protection is one of the most important research topics in nucleotide synthesis. ${ }^{1}$

The exocyclic amino protection of cytidine is required for creating the building blocks for oligonucleotide synthesis and for making important biological cytidine derivatives, such as 2',3'-dideoxycytidine a potential antiviral agent, particularly against human immuno-deficiency virus (HIV). ${ }^{2}$ Thus, costeffective methods are needed for the manufacturing of these drugs at commercial scales. Attempts have been made from time to time to achieve the selective protection of the amino function in cytidine derivatives. The procedure developed by Khorana et al. was the peracylation of the nucleosides followed by selective $O$-deacylation. ${ }^{3}$ Jones's group used a transient protection method with sequential three steps, involving the protection of the free alcohol groups as silyl ether, $N$-acylation and the desilylation of the alcohol groups using a weak base. ${ }^{4}$ Conventionally, most of the reagents for protection are either acid chlorides or anhydride forms. There can be several drawbacks to using these approaches, such as; first, these methods involve various protection/deprotection steps resulting in decreased yields and increased impurities. Secondly, since excess acylating agent is generally required, valuable free acid is wasted. Moreover, some anhydrides are either expensive or not readily available and must be synthesized, requiring a time-consuming process to prepare. For example, isopropoxy-acetic anhydride was synthesized in a two-steps process from isopropoxyacetic chloride and its trimethylsilyl derivative. ${ }^{5}$ The Sinha group reported the $N$-acylation of transiently protected adenine and cytidine nucleosides with freshly prepared $N$-acylimidazoles. ${ }^{6}$ This method also required the removal of silyl groups via hydrolysis. Although this method offers the advantages of mono- acylation, the method requires absolutely dry reaction conditions and fresh preparation of the acylating reagent. The Bhat group used $N$-benzoyl tetrazole for the benzoylation of cytosine and adenine, and this method also requires the masking of the free hydroxyl group and is also limited to benzoylation. ${ }^{7}$

The direct selective protection of the exocyclic amine of nucleoside without temporary masking of the hydroxyl group has been rarely observed ${ }^{8}$. Recently, acetylated benzotriazole has been used; however, this two-step approach has certain drawbacks, such as a) harsh reaction conditions, b) unsuitable for benzoylation. ${ }^{9}$ The other one was use of $p$-nitro phenol ester. ${ }^{10}$ This strategy needs a catalyst and also a coupling agent such as dicyclohexyl carbodiimide (DCC). A more serious disadvantage of this method is significant contamination of the product with dicycohexyl urea (DCU), which is a byproduct of the reaction. These difficulties prompted us to look for a mild one-step acylating reagent that would give the monoacylated product directly and that would be suitable for multigram scales and would use most of the acids as economically as possible.

Over the last few years, there has been considerable application of cyanuric chloride or its derivatives in organic synthesis. ${ }^{11-14}$ 2-Chloro-4,6-dimethoxy-1,3,5-triazine (CDMT) was recently found to have applications as a condensing reagent in peptide chemistry. ${ }^{15}$ The activation of carboxylic acids by means of CDMT is a multistep process and was elegantly and thoroughly examined by Kaminski. ${ }^{16}$ CDMT was used for the in situ activation of the carboxylic group in many transformations, such as the synthesis of $N$-methoxy- $N$-methyl amides, ${ }^{17}$ aldehydes, ${ }^{13}$ ketones or $\alpha$-amino ketones, ${ }^{18} 2$-oxazolines, ${ }^{19}$ monoacylated piperazine. $^{20}$

Here, we describe our success in using CDMT for the in situ activation of carboxylic acid to synthesize $N^{4}$-acetyl, benzoyl and phenoxy acetyl derivatives of cytidine and 2'-deoxycytidine. The acylation of the exocyclic amine was carried out in a one-step process. Instead of using acyl halides or anhydrides, our strategy involves the enhancement of the reactivity of the carbonyl group of the acid moiety using the 4,6-dimethoxy1,3,5-triazine group. In standard procedures, first the CDMT reacts with $N$-methyl morpholine (NMM) to form 4-(4,6-dimethoxy-1,3,5-triazin-2-yl)-4-methylmorpholinium chloride, and then the carboxylic acid is added to generate an active ester 1 (Scheme 1).

This resulting reaction mixture was further treated with a 
Table 1. $N$-Acetylation of the 2'-deoxycytidine in different reaction conditions with activated acetic acid

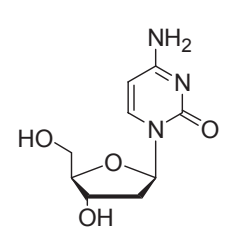

dC

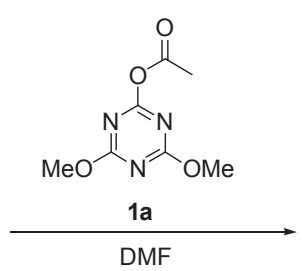

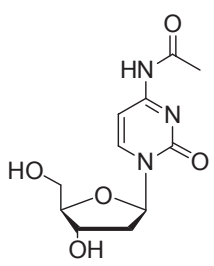

$N$-acetyl-dC

\begin{tabular}{ccccc}
\hline Entry & Eqiv. of $\mathbf{1 a}^{a}$ & Temp. $\left({ }^{\circ} \mathrm{C}\right)$ & Time $(\mathrm{h})$ & Yield $(\%)^{b}$ \\
\hline 1 & 1 & 25 & 12 & 66 \\
2 & 2.5 & 25 & 12 & 76 \\
3 & 5 & 25 & 12 & 60 \\
4 & 2.5 & 25 & 6 & 65 \\
5 & 2.5 & 50 & 6 & 85 \\
\hline
\end{tabular}

${ }^{a}$ Addition equivalent of 1 a compared to the nucleoside. ${ }^{b_{0}} \%$ yields of product were calculated from the NMR experiment of the crude mixture.<smiles>COc1nc(Cl)nc(OC)n1</smiles>

1) $\mathrm{NMM} / \mathrm{CH}_{2} \mathrm{Cl}_{2}, 0^{\circ} \mathrm{C}$

2) $\mathrm{R}_{1} \mathrm{COOH} / \mathrm{DMF}, \mathrm{rt}$

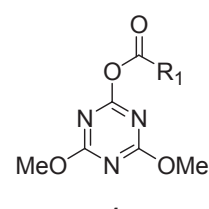

$$
\mathrm{R}_{1}=-\mathrm{CH}_{3},-\mathrm{Ph},-\mathrm{CH}_{2} \mathrm{OPh}
$$

Scheme 1. In situ generation of active ester of CDMT

nucleoside to afford the $N$-acylated nucleoside. The by-products, such as $N$-methylmorpholine hydrochloride and the triazine derivative were removed by aqueous work-up, and the desired $\mathrm{N}$-acylated product was purified easily by silica gel column chromatography. To optimize the reaction condition, acetylation reactions of 2'-deoxycytidine were carried out in the different molar combinations of the acylating agent (1a) and in the different reaction temperature for the synthesis of $N^{4}$-acetyl-2'-deoxycytidine (Table 1).

First, the optimum reaction times were chosen by monitoring the complete consumption of the starting materials in each reaction condition using thin-layer chromatography. At room temperature, the starting materials were not fully converted into the products after overnight reaction, although excess acylating agents compared to the starting material (SM) were added. After overnight reaction, the solvent evaporated and the NMR spectra of the crude mixture were obtained to calculate the yield of the product. As shown in Table 1, the maximum yield at room temperature was achieved in the presence of 2.5 equivalents of the acylating agent (entry 2). Although no other side product was detected in the NMR spectrum, SMs were not fully consumed after overnight reaction. Excess addition of 1a ( 5 eq.) produced the mixture of the target product and undesired side products, $\mathrm{O}$-acetylated and/or $\mathrm{N}, \mathrm{O}$-diacetylated nucleoside, thereby reducing the overall yield of the product (entry 3 ). However, the addition of one equivalent of the acylating agent showed less conversion of the starting material to the product,

Table 2. Selective $N$-acylation of the 2'-deoxycytidine and cytidine
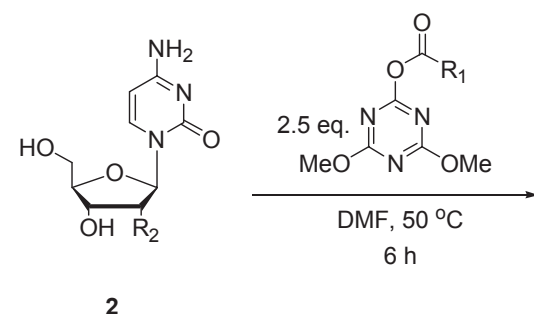

$6 \mathrm{~h}$

\begin{tabular}{ccccc}
\hline Entry & Products & $\mathrm{R}_{1}$ & $\mathrm{R}_{2}$ of $\mathbf{2}$ & ${\text { yield }(\%)^{a}}^{a}$ \\
\hline 1 & $\mathbf{3 a}$ & $\mathrm{CH}_{3}$ & $\mathrm{H}$ & 80 \\
2 & $\mathbf{3 b}$ & $\mathrm{CH}_{3}$ & $\mathrm{OH}$ & 93 \\
3 & $\mathbf{3 c}$ & $\mathrm{Ph}$ & $\mathrm{H}$ & 80 \\
4 & $\mathbf{3 d}$ & $\mathrm{Ph}$ & $\mathrm{OH}$ & 85 \\
5 & $\mathbf{3 e}$ & $\mathrm{CH}_{2} \mathrm{OPh}$ & $\mathrm{H}$ & 81 \\
6 & $\mathbf{3 f}$ & $\mathrm{CH}_{2} \mathrm{OPh}$ & $\mathrm{OH}$ & 91 \\
\hline
\end{tabular}

${ }^{a}$ Isolated yield after silica column chromatography.

without formation of any side products. In contrast to room temperature, all reactants were fully consumed in $6 \mathrm{hr}$ at $50{ }^{\circ} \mathrm{C}$ (entry 5 in Table 1). The maximum yield of the product reached around $85 \%$, and few side products were detected in the crude NMR spectrum.

Next, this method was applied to the synthesis of $N$-acyl derivatives of 2'-deoxycytidine and cytidine using different carboxylic acids. As shown in Table 2, despite the addition of different acylating agents, that were generated in situ from acetic acid, benzoic acid and phenoxy acetic acid, respectively, the isolated yields of selective $N$-acyl derivatives of 2'-deoxycytidine were around $80 \%$ after purification by chromatography (entry 1, 3, 5 in Table 2). Despite the increased presence of the free hydroxyl groups in cytidine, the yields of $N$-acyl derivatives of cytidine were slightly higher than that of 2'-deoxycytidine (entry 2, 4, 6). This implies that the free hydroxyl groups of the nucleosides did not interfere with the acylation of the exocyclic amine in this condition.

A similar observation has been made by the Bandgar group for selective mono $\mathrm{N}$-acylation of 2-hydroxy ethyl piperazine by using acyloxy triazine. ${ }^{20}$ Due to the steric hindrance present in the 4,6-dimethoxy-1,3,5-triazine intermediate (1), no bis$\mathrm{N}$-acylation was detected. In the absence of a base such as $\mathrm{N}, \mathrm{N}$-dimethyl aminopyridine (DMAP), the corresponding monoacylated nucleosides were obtained in good yields (80 - 93\%). Interestingly, the majority of $O$-acylated product was formed when DMAP was added to the reaction. This observation suggests a possible reaction mechanism involving a direct nucleophilic attack of the exocyclic amino group of the nucleoside on the intermediate (1). An attempt was made to synthesize the $\mathrm{N}$-benzoyl analogue of 2'-deoxyadenosine and 2'-deoxyguanosine, but was found to be unsuitable. The acylation of the 2 -deoxyadenosine by this method resulted in less conversion and produced a mixture of $\mathrm{N}$ - and $\mathrm{O}$-acylated products. Under the same acylation condition (Table 2), 2'-deoxyguanosine was found to be unreactive. Due to the presence of strong nucleophilic amine compared to the exocyclic amine of the 2'-deoxy- 
adenosine and 2'-deoxyguanosine, this method only works with cytidine derivatives.

Although this methodology is not useful for selective $N$-acylation of adenosine and guanosine, this methodology is found to be general for selective $\mathrm{N}$-acylation of cytidine. To our knowledge, no general method has been reported previously that is single-step and useful for all protecting groups, such as acetyl, benzoyl, and phenoxyacetyl, in which the protecting group have been installed on the base moiety of cytidine and 2'-deoxycytidine without prior $O$-protection and in the absence of a catalyst. Additionally, present methodology may be extended to a variety of selective $N$-acylation of cytidine using other carboxylic acids such as $t$-butylphenoxyacetyl ( $t$-BPA), ${ }^{21}$ isopropyl-phenoxyacetyl (IPAC), and isopropoxyacetyl (IPOAC) ${ }^{5}$ to achieve milder and faster deprotection in the oligonucleotides synthesis.

In comparison with other conventional methods, the strategy presented here eliminates the need for the temporary masking of the free hydroxyl groups that are required in conventional two step procedures. The selectivity between $\mathrm{N}$-acylation and $O$-acylation in this method may have originated from the intrinsic stability of acylating intermediate and the difference of nucleophilicity of $N / O$ nucleophiles in the cytidine. This method is cost-effective and superior to conventional methods because the carboxylic acid can be used for one step synthesis without converting carboxylic acid to an acid chloride or an acid anhydride.

In summary, we have successfully developed a one-flask convenient and straightforward method for the selective preparation of $N^{4}$-acetyl, benzoyl and phenoxy acetyl derivatives of cytidine and 2'-deoxycytidine by using a 1:2.5 stoichiometry of nucleoside to acylating reagent. The method can be used as a valid alternative to conventional methods, thereby avoiding the transient protection of the hydroxyl groups and, consequently, any tedious subsequent deprotection reaction. Furthermore, this process is amenable to scaling-up. The selectivity in $N$-acylation, mild reaction conditions and the use of inexpensive and easily available reagents are noteworthy advantages of this method.

General method for $N$-acylation of 2'-deoxycytidine. The procedure for the preparation of $N^{4}$-acetyl-2'-deoxycytidine (3a) is representative for all cases: To a solution of 2-chloro4-6-dimethoxy-1,3,5-triazine (1.1 mmol) in $\mathrm{CH}_{2} \mathrm{Cl}_{2}(5 \mathrm{~mL})$, $\mathrm{N}$-methylmorpholine $(1.5 \mathrm{mmol})$ was added at $0-5^{\circ} \mathrm{C}$ under continuous stirring. A white suspension was formed after 30 $40 \mathrm{~min}$, and acetic acid $(1.1 \mathrm{mmol})$ was added directly to the mixture, resulting in the formation of a clear solution. After stirring the mixture for $1 \mathrm{~h}, 2^{\prime}$-deoxycytidine $(0.44 \mathrm{mmol}, 1 \mathrm{eq}$.) in the DMF solution ( $3 \mathrm{~mL}$ ) was added dropwise and heated to $50{ }^{\circ} \mathrm{C}$. After completion of the reaction (TLC, $6 \mathrm{~h}$ ), the reaction mixture was dried in vacuum to get gum, dissolved in a minimum amount of water, and extracted with EA $(4 \times 10 \mathrm{~mL})$. The organic layer was dried over a $\mathrm{Na}_{2} \mathrm{SO}_{4}$, filtered, and the solvent was removed by vacuo and the crude product easily purified by using flash column chromatography, eluting with a gradient system of $0-7 \%$ methanol in dichloromethane. All final products were characterized by ${ }^{1} \mathrm{H}-,{ }^{13} \mathrm{C}-\mathrm{NMR}$ and ESIMass.

\section{Characterization data of $\mathrm{N}$-acylated nucleosides.}

3a: ${ }^{1} \mathrm{H}$ NMR $\left(400 \mathrm{MHz}, \mathrm{DMSO}-d_{6}\right) \delta 10.84(\mathrm{~s}, 1 \mathrm{H}), 8.31$ (d, $1 \mathrm{H}), 7.17(\mathrm{~d}, 1 \mathrm{H}), 6.09(\mathrm{~m}, 1 \mathrm{H}), 5.25(\mathrm{~m}, 1 \mathrm{H}), 5.10(\mathrm{~m}, 1 \mathrm{H})$, $4.21(\mathrm{~m}, 1 \mathrm{H}), 3.85(\mathrm{~m}, 1 \mathrm{H}), 3.58(\mathrm{~m}, 2 \mathrm{H}), 2.28(\mathrm{~m}, 1 \mathrm{H}), 2.0(\mathrm{~s}$, $3 \mathrm{H}), 1.99(\mathrm{~m}, 1 \mathrm{H}) ;{ }^{13} \mathrm{C}$ NMR $\left(100 \mathrm{MHz}, \mathrm{DMSO}-d_{6}\right) \delta 171.92$, $162.29,154.51,145.02,95.25,87.93,86.18,69.95,60.96$, 40.92, 24.37; ESI-Mass ( $\mathrm{m} / \mathrm{z}$ ); calcd. 269.10; found, 292.09 $[\mathrm{M}+\mathrm{Na}]$.

3b: ${ }^{1} \mathrm{H}$ NMR (400 MHz, DMSO- $\left.d_{6}\right) \delta 10.84(\mathrm{~s}, 1 \mathrm{H}), 8.39$ $(\mathrm{d}, 1 \mathrm{H}), 7.15(\mathrm{~d}, 1 \mathrm{H}), 5.75(\mathrm{~m}, 1 \mathrm{H}), 5.44(\mathrm{~m}, 1 \mathrm{H}), 5.14(\mathrm{~m}, 1 \mathrm{H})$, $5.03(\mathrm{~m}, 1 \mathrm{H}), 3.94(\mathrm{~m}, 1 \mathrm{H}), 3.88(\mathrm{~m}, 1 \mathrm{H}), 3.70(\mathrm{~m}, 1 \mathrm{H}), 3.60$ $(\mathrm{m}, 1 \mathrm{H}), 2.07(\mathrm{~s}, 3 \mathrm{H}) ;{ }^{13} \mathrm{C}$ NMR $\left(100 \mathrm{MHz}, \mathrm{DMSO}-d_{6}\right) \delta 171.71$, 162.98, 155.37, 146.07, 95.86, 90.80, 84.88, 75.21, 69.37, 60.60, 25.0; ESI-Mass $(\mathrm{m} / \mathrm{z})$; calcd. 285.09; found, $308.08[\mathrm{M}+\mathrm{Na}]$.

3c: ${ }^{1} \mathrm{H}$ NMR (400 MHz, DMSO- $\left.d_{6}\right) \delta 11.21(\mathrm{~s}, 1 \mathrm{H}), 8.37$ (d, $1 \mathrm{H}), 7.97(\mathrm{~m}, 2 \mathrm{H}), 7.6(\mathrm{~m}, 1 \mathrm{H}), 7.48(\mathrm{~m}, 2 \mathrm{H}), 7.33(\mathrm{~d}, 1 \mathrm{H}), 6.11$ $(\mathrm{m}, 1 \mathrm{H}), 5.25(\mathrm{~m}, 1 \mathrm{H}), 5.04(\mathrm{~m}, 1 \mathrm{H}), 4.21(\mathrm{~m}, 1 \mathrm{H}), 3.85(\mathrm{~m}$, $1 \mathrm{H}), 3.59(\mathrm{~m}, 2 \mathrm{H}), 2.29(\mathrm{~m}, 1 \mathrm{H}), 2.03(\mathrm{~m}, 1 \mathrm{H}) ;{ }^{13} \mathrm{C}$ NMR $(100$ MHz, DMSO- $\left.d_{6}\right) \delta 168.00,163.61,154.99,145.60,133.88$, 133.38, 129.12 (4C), 96.74, 88.62, 86.89, 70.60, 61.62, 41.60; ESI-Mass $(\mathrm{m} / \mathrm{z})$; calcd. 331.11; found, $354.10[\mathrm{M}+\mathrm{Na}]$.

3d: ${ }^{1} \mathrm{H}$ NMR $\left(400 \mathrm{MHz}, \mathrm{DMSO}-d_{6}\right) \delta 11.25(\mathrm{~s}, 1 \mathrm{H}), 8.50(\mathrm{~d}$, $1 \mathrm{H}), 8.01(\mathrm{~m}, 2 \mathrm{H}), 7.62(\mathrm{~m}, 1 \mathrm{H}), 7.50(\mathrm{~m}, 2 \mathrm{H}), 7.32(\mathrm{~d}, 1 \mathrm{H})$, $5.81(\mathrm{~m}, 1 \mathrm{H}), 5.51(\mathrm{~m}, 1 \mathrm{H}), 5.23(\mathrm{~m}, 1 \mathrm{H}), 5.20(\mathrm{~m}, 1 \mathrm{H}), 4.01(\mathrm{~m}$, 2H), $3.92(\mathrm{~m}, 1 \mathrm{H}), 3.76(\mathrm{~m}, 1 \mathrm{H}), 3.58(\mathrm{~m}, 1 \mathrm{H}) ;{ }^{13} \mathrm{C}$ NMR $(100$ MHz, DMSO- $\left.d_{6}\right) \delta 168.00,165.65,155.20,146.02,133.84$, 133.41, 129.12 (4C), 96.71, 90.84, 84.94, 75.25, 69.34, 60.56; ESI-Mass $(\mathrm{m} / \mathrm{z})$; calcd. 347.11; found, $370.10[\mathrm{M}+\mathrm{Na}]$.

3e: ${ }^{1} \mathrm{H}$ NMR $\left(400 \mathrm{MHz}, \mathrm{DMSO}-d_{6}\right) \delta 10.97(\mathrm{~s}, 1 \mathrm{H}), 8.36(\mathrm{~d}$, $1 \mathrm{H}), 7.28(\mathrm{~m}, 2 \mathrm{H}), 7.13(\mathrm{~d}, 1 \mathrm{H}), 6.90,6.97(\mathrm{~m}, 3 \mathrm{H}), 6.10(\mathrm{~m}$, $1 \mathrm{H}), 5.26(\mathrm{~m}, 1 \mathrm{H}), 5.05(\mathrm{~m}, 1 \mathrm{H}), 4.82(\mathrm{~s}, 2 \mathrm{H}), 4.21(\mathrm{~m}, 1 \mathrm{H})$, $3.85(\mathrm{~m}, 1 \mathrm{H}), 3.59(\mathrm{~m}, 2 \mathrm{H}), 2.29(\mathrm{~m}, 1 \mathrm{H}), 2.01(\mathrm{~m}, 1 \mathrm{H}) ;{ }^{13} \mathrm{C}$ NMR (100 MHz, DMSO- $\left.d_{6}\right) \delta 169.83,162.51,158.35,154.99$, $146.02,130.22,121.83,115.09,95.94,88.63,86.95,70.56$, 67.22, 61.58, 41.58; ESI-Mass $(\mathrm{m} / \mathrm{z})$; calcd. 361.12; found, $384.11[\mathrm{M}+\mathrm{Na}]$.

3f: ${ }^{1} \mathrm{H}$ NMR (400 MHz, DMSO- $\left.d_{6}\right) \delta 10.98(\mathrm{~s}, 1 \mathrm{H}), 8.46$ (d, $1 \mathrm{H}), 7.30(\mathrm{~m}, 2 \mathrm{H}), 7.11(\mathrm{~d}, 1 \mathrm{H}), 6.93(\mathrm{~m}, 3 \mathrm{H}), 5.78(\mathrm{~m}, 1 \mathrm{H})$, $5.49(\mathrm{~m}, 1 \mathrm{H}), 5.15(\mathrm{~m}, 1 \mathrm{H}), 5.05(\mathrm{~m}, 1 \mathrm{H}), 4.82(\mathrm{~s}, 2 \mathrm{H}), 3.96(\mathrm{~m}$, 2H), $3.90(\mathrm{~m}, 1 \mathrm{H}), 3.73(\mathrm{~m}, 1 \mathrm{H}), 3.58(\mathrm{~m}, 1 \mathrm{H}) ;{ }^{13} \mathrm{C}$ NMR $(100$ MHz, DMSO- $\left.d_{6}\right) \delta 169.22,161.88,157.67,154.53,145.70$, $129.54,121.16,114.42$, 95.25, 90.23, 84.21, 74.56, 68.60, 66.56, 59.86; ESI-Mass ( $\mathrm{m} / \mathrm{z}$ ); calcd. 377.12; found, 400.11 $[\mathrm{M}+\mathrm{Na}]$.

Acknowledgments. This research was supported by the Basic Science Research Program through the National Research Foundation of Korea (NRF) funded by the Ministry of Education, Science and Technology (2009-0071513) and also supported by the Kyungwon University Research Fund in 2010.

\section{References}

1. Beaucage, S. L.; Iyer, R. P. Tetrahedron 1992, 48, 2223. (and references cited therein.)

2. Marcuccio, S. M.; Elmes, B. C.; Holan, G.; Middleton, E. J. Nucleosides \& Nucleotides 1992, 11, 1695.

3. Schaller, H.; Weimann, G.; Lerch, B.; Khorana, H. G. J. Am. Chem. Soc. 1963, 85, 3821 . 
4. Ti, G. S.; Gaffney, B. L.; Jones, R. A. J. Am. Chem. Soc. 1982, 104, 1316.

5. Uznanski, B.; Grajkowski, A.; Wilk, A. Nucl. Acids Res. 1989, 17,4863

6. Sinha, N. D.; Davis, P.; Schultze, L. M.; Upadya, K. Tetrahedron Lett. 1995, 36, 9277.

7. Bhat, B.; Sanghvi,Y. S. Tetrahedron Lett. 1997, 38, 8811.

8. Bhat, V.; Ugarkar, B. G.; Sayeed, V. A.; Grimm, K.; Kosora, N.; Domenico, P. A.; Stocker, E. Nucleosides \& Nucleotides 1989, 8, 179

9. Reid, A. K.; McHugh, C. J.; Richie, G.; Graham, D. Tetrahedron Lett. 2006, 47, 4201

10. Mishra, R.; Mishra ,S.; Diwedi, V.; Misra, K. Nucleic Acids Symposium Series 2006, 50(1), 7 .

11. De Luca, L.; Giacomelli, G.; Porcheddu, A. J. Org. Chem. 2002, 67,6272 .

12. Falchi, A.; Giacomelli, G.; Porcheddu, A.; Taddei, M. Synlett.
2000, 2, 273 .

13. Falorn i, M.; Giacomelli, G.; Porcheddu, A.; Taddei, M. J. Org. Chem. 1999, 64, 8962

14. Falorni, M.; Porcheddu, A.; Taddei, M. Tetrahedron Lett. 1999, 40, 4395.

15. Kaminski, Z. J. Biopolimers (Pept.Sci) 2000, 55, 140-164.

16. a) Kaminski, Z. J.; Paneth, P.; Rudzinski, J. J. Org. Chem. 1998, 63, 4248-4255. b) Kaminski, Z. J.; Kolesinska, B.; Kaminska, J. E.; Gora, J. J. Org. Chem. 2001, 66, 6276.

17. De Luca, L.; Giacomelli, G.; Taddei, M.J. Org. Chem. 2001, 66, 2534.

18. De Luca, L.; Giacomelli, G.; Porcheddu, A. Org. Lett. 2001, 3, 1519.

19. Bandgar, B. P.; Pandit, S. S. Tetrahedron Lett. 2003, 44, 2331.

20. Bandgar, B. P.; Pandit, S. S. Tetrahedron Lett. 2003, 44, 3855.

21. Sinha, N. D.; Davis, P.; Usman, N.; Perez, J.; Hodge, R.; Kremsky, J.; Casale, R. Biochimie 1993, 75, 13. 